\title{
A URGÊNCIA DO PRESENTE: ATITUDE CRÍTICA E ÉTICA DA LIBERDADE EM MICHEL FOUCAULT
}

\author{
Daniel Luís Cidade Gonçalves ${ }^{1}$
}

\begin{abstract}
Resumo:
Este trabalho parte do deslocamento - apontado por Frédéric Gros - no qual as análises foucaultianas desenvolvem uma nova concepção de subjetividade, verdade e filosofia. As implicações deste deslocamento são inúmeras e remetem principalmente aos conceitos de atitude crítica e ética da liberdade. A crítica é entendida como uma atitude filosófica que precisa ser reativada frequentemente, por problematizar as relações entre saber/poder/sujeito, sem pressupor nenhum privilégio cognitivo; e a ética entendida como o trabalho pelo qual o sujeito constitui a si mesmo. Ambas são vistas como exercícios de liberdade. Uma liberdade cujo alicerce é a possibilidade concreta de um questionamento constante da verdade e uma transformação permanente do sujeito. A liberdade, para Foucault, é algo que só existe em ato, uma prática que recebe sua significação na medida em que é exercida. A ideia a ser defendida aqui é a de que a atitude crítica com seu caráter ético pressupõe uma problematização permanente de nossas verdades, uma construção constante de nossas subjetividades e uma filosofia que atenda aos apelos da nossa atualidade. Assim como a liberdade; sujeito, verdade e filosofia são práticas que só fazem sentido na medida em que são efetivamente articuladas. É neste contexto que podemos diagnosticar e compreender o presente, para que, através de uma filosofia crítica e uma ética da liberdade, possamos mudar aquilo que nos pareça necessário ser mudado. O presente urge por novas práticas de liberdade, mas elas possuem o cuidado de si como pré-requisito, ou seja, só podemos fazer sua ontologia em termos de práticas de liberdade que pressupõem uma transformação do sujeito através de relações nas quais ele se engaja livremente.
\end{abstract}

Palavras-chave: Atitude crítica, ética da liberdade, cuidado de si, ontologia do presente.

\section{THE URGENCY OF THE PRESENT: CRITICAL ATTITUDE AND ETHICS OF FREEDOM IN MICHEL FOUCAULT}

\begin{abstract}
:
This work starts from the displacement - pointed out by Frédéric Gros - in which the Foucaultian analyzes develop a new conception of subjectivity, truth and philosophy. The implications of this displacement are numerous and refer mainly to the concepts of critical attitude and ethics of freedom. The critic is understood as a philosophical attitude that needs to be reactivated frequently, by problematizing the relations between knowledge/power/subject, without presupposing any cognitive privilege; and ethics is understood as the work by which the subject constitutes himself. Both are seen as exercises of freedom. A freedom whose foundation is the concrete possibility of a constant questioning of the truth and a permanent transformation of the subject. Freedom, for Foucault, is something that only exists in the act, a practice that receives its meaning when it is exercised. The idea to be defended here is that the critical attitude with its ethical character presupposes a permanent problematization of our truths, a constant construction of our subjectivities and a philosophy that responds to the appeals of our actuality. Just like freedom; subject, truth, and philosophy are practices that only make sense if they are effectively articulated. It is in this context that we can diagnose and understand the present, so that, through a critical philosophy and an ethic of freedom we can change what we think it needs to be changed. The present urges for new practices of freedom, but they presume the care of the self as a prerequisite, that is, we can only make their ontology in terms of freedom practices that presuppose a transformation of the subject through relations in which he engages freely.
\end{abstract}

Keywords: Critical attitude, ethic of freedom, care of the self, ontology of the present.

1 Doutor em Filosofia Política e Ética pela Universidade Federal de Santa Catarina. Mestre em Filosofia Política e Ética (2012) pela Universidade Federal de Santa Catarina. Possui Licenciatura em Filosofia pela Universidade Federal de Santa Catarina (2009) e Bacharelado em Filosofia pela Universidade Federal de Santa Catarina (2007). E-mail: daniel.cidade@gmail.com 


\section{A URGÊNCIA DO PRESENTE: ATITUDE CRÍTICA E ÉTICA DA... Daniel Luís Cidade Gonçalves}

\section{Introdução}

Segundo John Rajchman (1987), Foucault foi um dos grandes céticos de nosso tempo. Cético, contudo, não no sentido relativista em que qualquer crença é tão boa quanto qualquer outra. $\mathrm{O}$ ceticismo de Foucault pode ser diretamente relacionado com a questão da liberdade. Para o filósofo francês, não se trata de alcançar verdades seguras, mas de assegurar a nossa liberdade de recusar dogmas que nos são impostos (muitas vezes sob a alcunha de verdade) e nos livrar de restrições que frequentemente se apresentam a nós como necessárias. A liberdade de questionar qualquer dogma e recusar aqueles que nos parecem ultrapassados, prejudiciais, perniciosos e autoritários, implica no surgimento de novas possibilidades de pensamento e, consequentemente, em novas possibilidades de vida. Nas palavras de Rajchman:

\footnotetext{
Existe um fio condutor que atravessa esta reflexão e análise. É o que chamo a questão da liberdade. O questionamento do antropologismo por Foucault converte-se numa ética do livre pensamento: ao suspender a narrativa universalista e a segurança antropológica acerca de uma liberdade abstrata, Foucault dirige a nossa atenção para a liberdade bastante concreta de escrever, pensar e viver num questionamento permanente daqueles sistemas de pensamento e formas problemáticas de experiência em que nos encontramos. (RAJCHMAN, 1987, p. 11/12).
}

O trabalho intelectual de Foucault baseia-se no "direito de não estarmos convencidos". Sem que uma verdade, uma norma, uma lei, uma prática social, nos parece problemática, temos o direito de problematizar sobre ela, e quando necessário, propor mudanças. É exercendo este direito de não estar convencido que Foucault desenvolve uma serie de pesquisas, contempladas em obras como Vigiar a Punir e História da Loucura, nas quais, através do método arqueológico e genealógico, demonstra historicamente o que nos levou a propor o surgimento de instituições como a prisão e o asilo, assim como o que nos levou a compreendê-los como necessários.

Algumas breves palavras sobre a arqueologia e a genealogia nos farão compreender melhor. A arqueologia pode ser definida como uma análise histórica de diferentes tipos de saberes e diferentes tipos de discursos, encontrados em um contexto previamente delimitado. Para a arqueologia, não se trata de verificar se um dado saber em questão é verdadeiro, mas quais foram as condições históricas ocorrentes para que este saber pudesse ser tido como verdadeiro. Dessa forma, podemos dizer que a arqueologia não visa a estabelecer a verdade de um saber ou de um discurso, e sim,

\begin{tabular}{|c|c|c|c|c|}
\hline Q Rovista Dialectus & Ano 5 & n. 12 & Janeiro - Julho 2018 & p. $462-482$ \\
\hline
\end{tabular}




\section{A URGÊNCIA DO PRESENTE: ATITUDE CRÍTICA E ÉTICA DA... Daniel Luís Cidade Gonçalves}

investigar a sua condição de existência. Segundo a linha do método arqueológico, podemos dizer que o método genealógico não rompe completamente com seu antecessor. Antes disso, a genealogia engloba as pretensões históricas da arqueologia e inclui a análise das relações de poder, que corroboram os saberes em questão. Não existem saberes sem relações de poder que lhes sirvam de pano de fundo, positivandoos, transformando-os em verdades e utilidades, e, não existe poder sem um saber (um discurso) legitimando-o.

Com isso, podemos dizer que a genealogia não nega a análise das condições históricas do saber, mas acrescenta a importância de compreender como uma série de relações de poder encontram-se inseridas (e podem ser analisadas) sempre que algo vem a ser compreendido como verdadeiro em um determinado contexto. Assim, a genealogia rompe de maneira ainda mais forte com a ideia de uma "neutralidade do saber". A genealogia não nega a arqueologia, o que leva alguns estudiosos de Foucault a usarem o termo arqueogenealogia (2).

Dessa forma, podemos compreender a genealogia como o método proveniente da arqueologia, utilizado por Foucault com a intenção de fazer a crítica de algum tema específico, sem que para isso seja necessário recorrer a argumentos que pressuponham uma "natureza humana", ou a existência de "verdades universais". Ao demonstrar o caráter histórico de uma crença e as relações de poder que a corroboram, estamos demonstrando sua contingência e sua arbitrariedade e abrindo as portas para a nossa liberdade de surgir com novas crenças que nos pareçam mais apropriadas.

\section{Sujeito, Verdade e Filosofia}

De acordo com Frédéric Gros (2008), em um artigo intitulado "Verdade, Subjetividade, Filosofia no último Foucault”, as análises foucaultianas, principalmente aquelas referentes ao último eixo foucaultiano, consentem para o desenvolvimento de "uma nova concepção de subjetividade, uma nova concepção de verdade e uma nova concepção de filosofia" (GROS, 2008, p. 1). Contudo, é importante esclarecer que estas três novas concepções não são completamente independentes. Uma implica a outra. Não

\footnotetext{
Parece que este termo, que não foi utilizado por Foucault, surge como uma maneira de afirmar a ideia de que a genealogia não substitui a arqueologia, mas apenas amplia ainda mais o seu campo de atuação. Isto de fato é verdade, contudo, nos deparamos com o dilema de que poderia ser melhor utilizarmos o termo arqueogenealogia, a despeito de Foucault nunca ter o feito, ou, se devemos nos manter fiel ao autor, apenas apontando a genealogia como um ampliação da análise arqueológica, pressupondo assim, que o trabalho genealógico engloba o trabalho arqueológico como um todo.
}

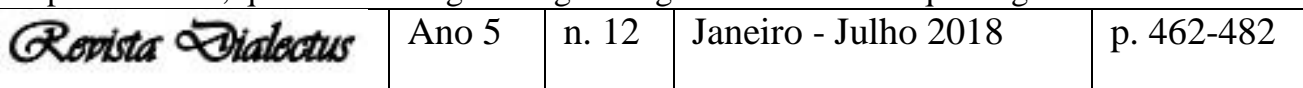




\section{A URGÊNCIA DO PRESENTE: ATITUDE CRÍTICA E ÉTICA DA... Daniel Luís Cidade Gonçalves}

seria possível, por exemplo, estabelecer uma nova concepção de filosofia sem pressupor uma nova concepção de subjetividade e verdade. Também é importante ressaltar que embora Foucault seja um autor extremamente original, que contribuiu indiscutivelmente para a filosofia contemporânea, seria um tanto exagerado pressupor que as modificações a serem apresentadas - que constituem uma nova concepção de subjetividade, verdade e filosofia - sejam exclusividade de Foucault. Existem diversos momentos de originalidade no autor, mas também existem uma série de críticas e deslocamentos que não são exclusividade de Foucault. Foucault não foi o primeiro nem o último a discutir a ideia de que talvez seria melhor abandonarmos a noção de uma natureza humana intrínseca a nós, ou a dizer que a verdade não é algo que está inscrito em nós ou na natureza, esperando ser descoberta. Mas com certeza, seus escritos exerceram uma influência fundamental para trabalharmos mais profundamente com isso.

Em primeiro lugar, abordarei as implicações acerca de uma nova concepção do sujeito. De acordo com Gros (2008, p.1), a tradição filosófica, seja com o "cogito cartesiano, o ego transcendental de Kant, ou a consciência intencional de Husserl", ressalta três grandes características acerca do sujeito: "o sujeito é essencial, é a priori, é transcendental" (GROS, 2008, p.1). As investigações de Foucault implicam um deslocamento (3) de tais concepções. Para Foucault, tais concepções remetem a pressupor uma racionalidade soberana a transcendental. Nesta tradição, o papel do filósofo (ou dos demais intelectuais), seria o de descobrir como corresponder a esta racionalidade existente em nós, da melhor maneira possível. Todavia, para Foucault, esta racionalidade una e soberana não existe. A racionalidade humana é historicamente constituída. Não podemos analisar a racionalidade humana como um todo, mas apenas analisar suas diferentes formas presentes em diversos momentos históricos, em diversas práticas sociais. Foucault vai mais além e alega que tais práticas sociais fazem surgir diferentes tipos de sujeito.

Meu objetivo será mostrar-lhes como as práticas sociais podem chegar a engendrar domínios de saber que não somente fazem aparecer novos objetos, novos conceitos, novas técnicas, mas também fazem nascer formas totalmente novas de sujeitos e de sujeitos de conhecimento. (FOUCAULT, 1996, p. 8).

Tendo isto em conta, Foucault questiona a noção essencialista do sujeito:

3 De acordo com Gros, trata-se de um deslocamento e não uma crítica frontal, porque as construções de Foucault não se situam no mesmo plano de seus "opositores". Não se trata de invalidar o idealismo filosófico, mas de deslocar a imagem do sujeito.

\begin{tabular}{|l|l|l|l|l|}
\hline Rovista Qialectus & Ano 5 & n. 12 & Janeiro - Julho 2018 & p. 462-482 \\
\hline
\end{tabular}




\title{
A URGÊNCIA DO PRESENTE: ATITUDE CRÍTICA E ÉTICA DA... Daniel Luís Cidade Gonçalves
}

\begin{abstract}
Atualmente, quando se faz história - história das ideias, do conhecimento ou simplesmente história - atemo-nos a esse sujeito de conhecimento, a este sujeito da representação, como ponto de origem a partir do qual o conhecimento é possível e a verdade aparece. Seria interessante tentar ver como se dá, através da história, a constituição de um sujeito que não é dado definitivamente, que não é aquilo a partir do que a verdade se dá na história, mas de um sujeito que se constitui no interior mesmo da história, e que é a cada instante fundado e refundado pela história. É na direção desta crítica radical do sujeito humano pela história que devemos nos dirigir. (FOUCAULT, 1996, p. 10).
\end{abstract}

Ligado a esta problemática de que o sujeito é constituído historicamente através de práticas sociais, Gros destaca três noções principais trabalhadas por Foucault; as técnicas de si, as práticas de subjetivação e o cuidado de si. O cuidado de si é a mais importante delas, mas antes, algumas palavras sobre as outras duas noções.

Quando Foucault fala de "técnicas de si", descreve as técnicas históricas mediante as quais o sujeito se constrói numa relação específica consigo mesmo através de um programa de exercícios, físicos e mentais, na perspectiva de um projeto de vida determinado. (GROS, p. 2)

Poderíamos ter como exemplo, a técnica de dominar as próprias paixões. Mas é importante ressaltar que não se trata de estabelecer uma essência eterna da subjetividade, mas de fornecer formas históricas que possam fornecer programas éticos de construção da existência. Todavia, isso não implica em dizer que o ser humano é um objeto passivo determinado pela história. Com o conceito de "prática de subjetivação", as técnicas de si passam a ser entendidas como "programas de estilização da existência que tem sentido unicamente dentro do horizonte da liberdade" (GROS, 2008, p. 2). Com isso, não se trata apenas de constituir-se, mas de transformar-se. O "si ético" foucaultiano é um sujeito que experencia sua própria transformação através de modalidades historicamente determinadas (como a ascese, a conversão, etc.).

É neste contexto de uma prática de subjetivação remetendo-se a um si ético que através das técnicas de si o sujeito constrói a si mesmo, mas principalmente transforma a si mesmo, que Foucault aborda a temática do "cuidado de si". No curso Hermenêutica do sujeito (1982), Foucault trabalha esta noção grega e latina (epimeleia heautou e cura sui), alegando que na antiguidade o famoso "conhece-te a ti mesmo", tinha que ser compreendido na perspectiva do cuidado de si.

O que interessa Foucault no cuidado de si dos antigos é que é totalmente irredutível a uma introspecção psicológica. Não pressupõe nenhuma investigação da própria identidade secreta, nenhuma investigação sobre a

\begin{tabular}{|l|l|l|l|l|}
\hline Govista Dialectus & Ano 5 & n. 12 & Janeiro - Julho 2018 & p. 462-482 \\
\hline
\end{tabular}




\section{A URGÊNCIA DO PRESENTE: ATITUDE CRÍTICA E ÉTICA DA... Daniel Luís Cidade Gonçalves}

própria intimidade. Tomar cuidado de si é submeter-se a um certo número de exercícios, não para se conhecer melhor, mas para intensificar a presença junto a si mesmo. O tomar cuidado de si é uma forma de atenção e de vigilância para consigo mesmo, que não age segundo o modo da decifração. O que importa é recolher-se, concentrar-se, e não decifrar a própria identidade secreta. (GROS, 2008 p. 2).

De acordo com o autor, a noção de "cuidado de si" constitui, no mundo greco-romano, o modo através do qual a liberdade foi pensada como ética. Para praticar adequadamente a liberdade, era necessário cuidar de si. Foucault nos mostra, com sua análise dos textos antigos, que cuidar de si mesmo era um tema importante, na medida em que era uma forma de construir sua própria subjetividade de maneira livre, possibilitava uma ascese sobre si mesmo e fortalecia a busca de uma vida esteticamente bela. Mas é importante esclarecer que o cuidado de si não se remete apenas a um olhar individualista sobre si mesmo, o cuidado de si é uma prática social que pressupõe o outro.

As técnicas psicológicas de si, cujo paradigma é a confissão cristã, constroem aquela que se poderia chamar uma profundidade psicológica. As técnicas ascéticas de si, cujo paradigma é o cuidado de si nos gregos, pelo contrário, constroem uma exterioridade ética. O problema não consiste, para os antigos, em aprofundar uma identidade íntima, mas sim em construir eu forte, que possa responder às solicitações do mundo. Poder-se-ia resumir isso dizendo que Foucault procura voltar a uma questão esquecida: não "quem sou eu", mas "qual forma dar à minha existência"? (GROS, 2008, p. 2).

Com estes três conceitos, Foucault tenta se desvencilhar da matriz prática da confissão cristã, na qual o sujeito é visto como determinado por uma identidade secreta que seria preciso descobrir, e da matriz transcendental, onde o sujeito é entendido como instância pura do conhecimento.

O elo que liga a questão do sujeito com a da verdade, pode ser melhor compreendido com a distinção entre filosofia e espiritualidade. Para Foucault, durante toda a Antiguidade o tema da filosofia (como ter acesso à verdade?) e a questão da espiritualidade (quais são as transformações no sujeito necessárias ao acesso à verdade?) nunca estiveram separadas. "Espiritualidade" pode ser entendida aqui como a concepção de que a verdade não pode ser alcançada pelo sujeito no simples ato de conhecimento, pois para ter acesso a ela o sujeito deve olhar para si mesmo de modo a modificar-se, converter-se, alterar seu próprio ser, enquanto "filosofia" pode ser entendida como as consequências do conhecimento, sem que haja necessidade de transformação do sujeito, na medida em que é a estrutura que precisa ser assegurada

\begin{tabular}{|l|l|l|l|l|}
\hline Govista Qialectus & Ano 5 & n. 12 & Janeiro - Julho 2018 & p. 462-482 \\
\hline
\end{tabular}




\section{A URGÊNCIA DO PRESENTE: ATITUDE CRÍTICA E ÉTICA DA... Daniel Luís Cidade Gonçalves}

como condição de acesso à verdade. Foucault aponta Aristóteles como a única exceção de filósofo para o qual a questão da espiritualidade foi menos importante (fazendo-o fundador da filosofia moderna). De fato, Foucault alega que a história da verdade entrou no seu período moderno no dia em que admitimos que o que permite o acesso à verdade é o conhecimento e apenas o conhecimento. Para o filósofo de Poitiers, este seria o "momento cartesiano", pois foi Descartes o primeiro a realizá-lo. Contudo, isto não implica que o corte tenha sido feito definitivamente. Temos o conhecimento ligado às exigências de espiritualidade em diversos filósofos célebres, tais como Hegel, Schopenhauer, Nietzsche, entre outros.

\footnotetext{
Se é verdade, como dizem todos os cientistas, que podemos reconhecer uma falsa ciência pelo fato de que, para ser acessível, ela demanda uma conversão do sujeito e promete, ao termo de seu desenvolvimento, uma iluminação do sujeito; se podemos reconhecer uma falsa ciência pela sua estrutura de espiritualidade (isto é evidente, todos os cientistas o sabem), não se deve esquecer que, em formas de saber que não constituem precisamente ciências, e que não devemos assimilar à estrutura própria da ciência, reencontramos, de maneira muito forte e muito nítida, alguns elementos ao menos, algumas exigências da espiritualidade. (FOUCAULT, 2006a, p. 39).
}

Uma vez que o sujeito constrói e transforma a si mesmo através de práticas de subjetivação, tais como o cuidado de si, aquilo que ele irá aceitar como verdadeiro ou falso, não depende somente das características inerentes ao sujeito analisado, nem mesmo a algo transcendental inserido na natureza humana. As próprias alterações no sujeito alteram aquilo que será posteriormente aceito como verdadeiro nas relações entre saber e poder. Para Foucault, a espiritualidade não se encontra desvencilhada da filosofia, o sujeito não se encontra alheio à verdade. É importante aqui, abordar o que seria esta nova concepção de verdade.

De acordo com Gros (2008), para analisarmos os deslocamentos de Foucault com relação ao conceito de verdade, é necessário analisarmos três noções: a veridição (4), o dizer verdadeiro e a verdadeira vida.

Em primeiro lugar, acerca do tema da veridição, podemos constatar que o termo se refere ao "ato de tornar-se verdade" (GROS, 2008, p. 3). Segundo Gros, a investigação foucaultiana não é epistemológica, transcendental ou metafísica, na medida em que não procura estabelecer critérios de verdade, não tem a intenção de estabelecer as condições a priori de um conhecimento verdadeiro, nem investiga o que acontece

\footnotetext{
${ }^{4}$ Neologismo Foucaultiano.

\begin{tabular}{|l|l|l|l|l|}
\hline Qevista Q Dialectus & Ano 5 & n. 12 & Janeiro - Julho 2018 & p. 462-482 \\
\hline
\end{tabular}
}




\section{A URGÊNCIA DO PRESENTE: ATITUDE CRÍTICA E ÉTICA DA... Daniel Luís Cidade Gonçalves}

com o ser essencial da verdade. O problema de Foucault é o da "descrição das técnicas históricas a partir dos quais se produzem enunciados verdadeiros numa sociedade" (GROS, 2008, p.3). Cada cultura possui dispositivos diversos, concorrendo entre si, que definiriam o que esta cultura aceita como verdadeiro ou falso. Foucault não tem a intenção de avaliar a legitimidade, a verdade ou a eficácia de tais dispositivos, o problema dele "não é o da estrutura intrínseca da verdade, mas o da existência social da mesma". (GROS, 2008, p. 3).

Em segundo lugar, falemos da expressão "dizer verdadeiro" (le dire vrai), que aparece como tradução do termo grego parrhesia. Segundo Gros, o termo parrhesia é estudado por Foucault em um contexto político:

[...] trata-se, por exemplo, de qualificar o regime de palavra do cidadão livre que num contexto democrático, faz valer a sua concepção do bem comum, ou então, se trata também de qualificar o regime de palavra do filósofo que se dirige corajosamente ao Príncipe para lhe fazer críticas. Mas a parrhesia qualifica igualmente a atitude de Sócrates e dos cínicos que não hesitam em fazer críticas aos seus concidadãos e em estigmatizar violentamente os seus defeitos. (GROS, 2008, p. 4).

A parrhesia consiste em assumir os riscos de dizer a verdade. $\mathrm{O}$ que interessa aqui, para Foucault, é a verdade como atividade, a verdade como prática. Trata-se de "descrever o movimento concreto de afirmação de uma verdade no interior de um jogo político, descrever as práticas de verdade no interior de uma sociedade". (GROS, 2008, p.4).

Segundo Ortega (1999), em 1982, Foucault analisa uma noção de verdade enraizada na tradição da espiritualidade. Neste contexto, a verdade como espiritualidade não "consiste na recompensa do ato cognoscitivo, mas em algo que tem a possibilidade de iluminar, de transformar e transfigurar o sujeito" (ORTEGA, 1999, p. 104). A verdade aqui não é entendida como uma essência a ser descoberta nos indivíduos, mas como um trabalho a ser desenvolvido sobre si mesmo. Verdade como produção, verdade como êthos. É neste contexto que surge o tema da parrhesia.

Na parrhesia, o que importa não são as condições lógicas da verdade, mas os efeitos ascéticos e de constituição do sujeito produzidos pela mesma sobre aquele que a pronuncia. Neste caso, o sujeito atinge, através da produção de enunciados verdadeiros, uma nova forma de existência (dramática do discurso). Podemos dizer então, que se trata da "constituição de si mediante o cuidado constante da verdade" (ORTEGA, 1999, p. 109).

\begin{tabular}{|l|l|l|l|l|}
\hline Govista Dialectus & Ano 5 & n. 12 & Janeiro - Julho 2018 & p. 462-482 \\
\hline
\end{tabular}




\title{
A URGÊNCIA DO PRESENTE: ATITUDE CRÍTICA E ÉTICA DA... Daniel Luís Cidade Gonçalves
}

Ortega comenta sobre como é interessante encontrar esta noção de verdade em Foucault, tendo em vista sua obra prévia que consiste em um ataque imperativo a verdade, especialmente sobre si, como as práticas confessionais baseadas em uma confissão exaustiva e uma obediência incondicional.

\begin{abstract}
No desenvolvimento ulterior das técnicas de poder pastoral - desembocando no bio-poder e na psicanálise - permanece um elemento constante: a incitação à "descoberta de si", à busca da verdade interior, está estreitamente relacionada com a possibilidade de governar e ser governado. Toda a obra de Foucault pode ser interpretada neste sentido. Nas sociedades modernas incitase constantemente o indivíduo a buscar e descobrir a verdade que reside na sua alma: verdade de seu sexo, de sua identidade etc. Ele está convencido de que dizer a verdade constitui uma prática libertadora. A vontade de saber é uma tentativa de desmontar essa hipótese denominada "hipótese repressiva", dando lugar a uma genealogia das modernas práticas confessionais como dispositivo de saber/poder. (ORTEGA, 1999, p. 119).
\end{abstract}

Para Ortega, na década de 70, a verdade se encontra a serviço das técnicas de subjetivação modernas (aparelhos confessionais, psicanálise). É somente com a introdução do terceiro eixo foucaultiano que a verdade passa a ser entendida como prática de liberdade, como parrhesia.

É problemático, não obstante, que a parrhesía - mais do que outras tecnologias de si -, mediante sua incorporação ao poder pastoral e posteriormente aos aparelhos confessionais e às modernas técnicas de autodeciframento, tenha servido para a constituição dos indivíduos como sujeitos, objetos de um poder subjetivante. Infelizmente, a história das práticas parrhesiasticas conduz à hermenêutica do desejo e às práticas confessionais. Contudo, as análises foucaultianas da parrhesía têm como objetivo estimular a procura de novas formas de relação com a verdade, que, analogamente ao que acontecia com a parrhesia na Antiguidade, contribuam para a constituição de uma subjetividade não normativizada como prática libertadora. Em outras palavras, Foucault nos convida a escapar dos "jogos de verdade" da psicanálise e das técnicas de implantação de identidade (dispositivo da sexualidade, bio-poder) mediante a busca de novas formas do “dizer verdadeiro". (ORTEGA, 1999, p. 120).

Ainda com Ortega (1999), o dizer verdadeiro dirige-se a uma relação com a verdade que se encontra além de conhecimentos científicos. Temos a parrhesia como uma forma de vida. Para Ortega, Foucault busca reabilitar a tradição filosófica da espiritualidade como "uma tentativa de devolver ao indivíduo a liberdade e a verdade que lhes foram arrebatadas pela hermenêutica do desejo e do bio-poder" (ORTEGA, 1999, p. 121).

Por último, surge o conceito de verdadeira vida, que remete a escola dos cínicos antigos (que não possuíam uma doutrina ou uma filosofia como sistema

\begin{tabular}{|l|l|l|l|l|}
\hline Govista Dialectus & Ano 5 & n. 12 & Janeiro - Julho 2018 & p. 462-482 \\
\hline
\end{tabular}




\section{A URGÊNCIA DO PRESENTE: ATITUDE CRÍTICA E ÉTICA DA... Daniel Luís Cidade Gonçalves}

constituído de conhecimento). Segundo Foucault, o problema dos cínicos não era o de conhecer a verdade, mas o de constituir a própria existência como existência verdadeira, fazendo de suas vidas e de seus corpos o teatro escandaloso de uma verdade provocadora. Os cínicos recusam a discursividade da verdade, a verdade é algo que se vive.

Acerca da nova concepção de filosofia em Foucault, segundo Gros (2008), o filósofo francês se apoia na dupla herança de Kant e Platão (5). Em primeiro lugar, falemos de Foucault como herdeiro da tradição kantiana. Segundo Foucault, Kant fundou as duas tradições entre as quais se dividiu a filosofia moderna. A primeira foi fundada com suas três obras críticas, especialmente a primeira, que consiste em colocar a questão das condições em que um conhecimento verdadeiro é possível, fazendo com que toda uma seção da filosofia moderna se desenvolva como analítica da verdade. A segunda tradição fundada por Kant - e que parece ter merecido menos atenção - é a tradição que coloca a questão "o que é a atualidade?". Trata-se do que Foucault chama de uma "ontologia do presente", ou melhor, uma "ontologia de nós mesmos".

Nesta segunda tradição, trata-se das condições éticas da produção da verdade. "A disposição das Luzes, para Kant, é a coragem da verdade: "Sapere Aude"." (GROS, 2008, p. 6). Neste sentido, Foucault desloca-se da primeira tradição kantiana e se proclama herdeiro da segunda, na qual a coragem é entendida como a condição ética da verdade.

Ainda se remetendo a Kant, Foucault define a filosofia moderna como aquela que se refere à questão da atualidade. Segundo Gros:

Foucault com isso quis dizer sobretudo que é moderna para ele uma filosofia que responde não ao apelo da história, mas ao apelo da sua atualidade. A filosofia como filosofia moderna é uma filosofia que não se reflete como a retomada, a repetição de questões originárias, como um diálogo ininterrupto e atemporal entre grandes pensamentos eternos. Quando Foucault escreve que a filosofia moderna é aquela que põe a questão da atualidade não quer dizer que a filosofia moderna é aquela que toma a atualidade como seu objeto empírico, mas aquela que pensa a partir de uma convocação por parte da atualidade, ao invés de partir do chamamento da sua história imemorial. (GROS, 2008, p. 6)

Aqui é importante ressaltar que isso não faz de Foucault um kantiano ou um platônico, no sentido clássico do tema. Não é nas principais obras destes pensadores que Foucault se apoia (Crítica da Razão Pura, no caso de Kant, e A República, no caso de Platão), mas em textos marginais (O que é a Aufklärung, de Kant, e Carta VII, de Platão).

\begin{tabular}{|c|c|c|c|c|}
\hline Q Rovista Dialectus & Ano 5 & n. 12 & Janeiro - Julho 2018 & p. $462-482$ \\
\hline
\end{tabular}




\section{A URGÊNCIA DO PRESENTE: ATITUDE CRÍTICA E ÉTICA DA... Daniel Luís Cidade Gonçalves}

Em consonância com Gros (2008, p. 6): "O que leva a filosofia a pensar não é a história da filosofia, mas sim a urgência do presente". Por último, Foucault é compreendido como apoiado na herança platônica na medida em que Platão justifica sua viagem à Sićlia dizendo que a filosofia não deve ser apenas logos (discurso), mas também ergon (atividade prática). Na linha de Platão, Foucault pensa que a filosofia insere-se no interior de uma relação com a política.

Dizer que a filosofia encontra sua realidade no interior de uma certa relação com a política não equivale a dizer que ela deva refletir a verdade da política; mas nem sequer equivale a dizer que o filósofo deva empenhar-se politicamente para fazer triunfar as suas ideias. Esta posição de Foucault remete a uma ética do intelectual, concebida como crítica livre e corajosa das práticas políticas. (GROS, 2008, p. 6).

Segundo Gros, o ponto em comum entre estas novas concepções de subjetividade, verdade e filosofia é o "problema da realidade". Dessa forma, não se trata de considerar a realidade como algo externo e perguntar: "como um sujeito pode conhecer a realidade?", trata-se de "constituir uma ontologia histórica do sujeito, a partir de uma ontologia histórica da verdade" (GROS, 2008, p. 7).

Creio que a contribuição importante de Foucault para a filosofia consista em permitir-nos pensar de outra maneira a realidade. E seria preciso aqui introduzir um último conceito de Foucault: o de "problematização". É real o que faz problema, o que se torna problema, o que se problematiza na história dos homens. Algo se torna problema quando é objeto de discursos e de práticas de verdade, quando se torna uma aposta em jogo de poder nas relações entre os seres humanos, quando obriga os sujeitos a porem-se a questão da sua relação consigo mesmos. A realidade é aquilo que faz problema. Descrever as problematizações é, portanto, construir uma ontologia histórica da verdade e do sujeito.” (GROS, 2008, p. 7).

Dessa forma, a filosofia de Foucault desloca a questão sobre como conhecer a realidade, passando a investigar a cerca de como a mesma se constitui, usando o conceito de problematização como ferramenta de transformação.

\section{Atitude crítica e ética do livre pensamento}

Uma vez esclarecido o deslocamento foucaultiano acerca da subjetividade, da verdade e da filosofia, duas noções emergem como eixos norteadores do pensamento de Foucault: a crítica (ou atitude crítica) e a ética da liberdade (ou, para usar as palavras de Rajchman, a ética do livre pensamento).

A crítica está muito mais para um êthos, uma atitude filosófica que precisa ser reativada frequentemente. Não existem regras a serem seguidas, princípios que não

\begin{tabular}{|c|c|c|c|c|}
\hline Qevista Dialectus & Ano 5 & n. 12 & Janeiro - Julho 2018 & p. $462-482$ \\
\hline
\end{tabular}




\section{A URGÊNCIA DO PRESENTE: ATITUDE CRÍTICA E ÉTICA DA... Daniel Luís Cidade Gonçalves}

possam ser contestados ou limites que não possam ser ultrapassados. Isso leva o autor a utilizar, o termo atitude crítica. Não existe um fim último ou um momento final no qual todas as relações de poder estariam em perfeita harmonia. A crítica é uma atitude de constante interação com o poder, que por sua vez, está sempre sendo modificado. Segundo Foucault, a crítica se contrapõe ao poder pastoral, poder de origem cristã que desenvolveu a ideia de que todo indivíduo deve ser governado e dirigido à salvação numa relação de obediência. A partir do século XV esta concepção pastoral de poder, entendida como uma arte de governar explode fortemente e desloca-se do âmbito religioso, expandindo-se para a sociedade civil. Todavia, a explosão desta temática remete à questão inversa "como não ser governado demais", mas não em caráter absoluto. A questão emerge de forma parcial, formulada da seguinte maneira: "como não ser governados deste modo, em nome destes princípios, em vista de tais objetivos e através de tais procedimentos" (FOUCAULT, 1997, p. 2). Foucault define neste momento a atitude crítica como "a arte de não ser excessivamente governado".

A crítica está sempre em movimento, não busca um ponto de fuga que seria o núcleo da verdade e não se ancora em alguma entidade subjetiva a priori; como Deus, razão, consciência. Ela se realiza no mundo concreto, nas práticas discursivas e não discursivas, analisando suas origens e transformações. Segundo Foucault:

\footnotetext{
Mas o que é filosofar hoje em dia - quero dizer, a atividade filosófica - senão o trabalho crítico do pensamento sobre o próprio pensamento? Se não consistir em tentar saber de que maneira e até onde seria possível pensar diferentemente em vez de legitimar o que já se sabe? Existe sempre algo de irrisório no discurso filosófico quando ele quer, do exterior, fazer a lei para os outros, dizer-lhes onde está a sua verdade e de que maneira encontra-la, ou quando pretende demonstra-se por positividade ingênua: mas é seu direito explorar o que pode ser mudado no seu próprio pensamento, através do exercício de um saber que lhe é estranho. (FOUCAULT. 1988b, p. 13).
}

De acordo com Candiotto (2010 p. 113), “A atitude crítica atua como limite das artes de governar impedindo sua modificação embora jamais seu desaparecimento". A atitude crítica diante dos processos de governamentalização entende que nenhum poder é inevitável enquanto atua sobre os indivíduos. Compreendendo a governamentalização como o movimento pelo qual numa determinada prática social busca sujeitar os indivíduos por mecanismos de poder que se apoiam em justificações de verdade para reproduzir-se e legitimar-se, a atitude crítica é entendida como o processo pelo qual os indivíduos procuram "interrogar o poder [governo] nos seus efeitos de verdade" e a "verdade nos seus efeitos de poder". Para Foucault, não se trata

\begin{tabular}{|l|l|l|l|l|}
\hline Govista Dialectus & Ano 5 & n. 12 & Janeiro - Julho 2018 & p. 462-482 \\
\hline
\end{tabular}




\section{A URGÊNCIA DO PRESENTE: ATITUDE CRÍTICA E ÉTICA DA... Daniel Luís Cidade Gonçalves}

de buscar as condições de legitimidade do conhecimento científico/filosófico, temos que suspeitar do objetivismo, do positivismo, do tecnicismo que nos trouxeram um excesso de poder apoiado na verdade das ciências. Ao resistirmos ao governo da individualização podemos identificar diversos tipos de regimes de verdade que atuam na separação entre o verdadeiro e o falso. Quando o indivíduo passa a contestar essa ou aquela maneira de governar, pode vir a reconhecer a não-neutralidade desse ou daquele efeito de verdade a qual se encontra vinculado, e muitas vezes o entendia como necessário e universal. A atitude crítica leva em conta o esforço e a decisão de desprender-se do poder e propor uma política de verdade diferente, que consiste em uma análise dos limites e uma reflexão sobre eles.

[...] no que nos é apresentado como universal, necessário, obrigatório, qual é a parte do que é singular, contingente e fruto das imposições arbitrárias. Trata-se, em suma, de transformar a crítica exercida sob a forma de limitação necessária em uma crítica prática sob a forma de ultrapassagem possível. (FOUCAULT, 2000, p. 347)

É importante ressaltar que esta atitude histórico-crítica, para Foucault, deve ser entendida como uma atitude prática e experimental. Antes de tudo, ela deve abrir um domínio de pesquisas históricas, mas é de suma importância que ela se coloque à prova da realidade e da atualidade, buscando compreender os pontos em que a mudança é possível e desejável, e determinando a forma precisa a dar a ela. A crítica, ou a "ontologia histórica de nós mesmos", deve evitar projetos globais e radicais. É verdade que Foucault sempre preferiu mudanças parciais por sempre ter desconfiança das grandes teorias explicativas e a partir delas, de novos sistemas políticos que trarão a solução milagrosa para todos os nossos problemas.

Neste contexto podemos concordar com Cesar Candiotto, que em seu artigo intitulado Foucault: uma história crítica da verdade, afirma que o fio condutor do pensamento de Foucault é a problemática da verdade. Todavia, Foucault toma distância dos privilégios do sujeito de conhecimento e se foca na produção histórica da verdade. Assim, Foucault estabelece diferenças importantes entre a concepção clássica de verdade e sua concepção pessoal, denominada por Candiotto (2006) de "história crítica da verdade".

Na história crítica da verdade não há $o$ sujeito e $o$ objeto como unidades universais e necessárias; eles assim se tornam mediante práticas, que podem ser jogos teóricos e científicos, práticas sociais ou práticas de si. O distanciamento do sujeito constituinte e do objeto empírico dado torna a

\begin{tabular}{|c|c|c|c|c|}
\hline Qevista Q Dialectus & Ano 5 & n. 12 & Janeiro - Julho 2018 & p. $462-482$ \\
\hline
\end{tabular}




\section{A URGÊNCIA DO PRESENTE: ATITUDE CRÍTICA E ÉTICA DA... Daniel Luís Cidade Gonçalves}

problemática da verdade proposta pelo filósofo o modo de aplicação de uma "história crítica do pensamento". (CANDIOTTO, 2006, p. 66).

Para Foucault, o "verdadeiro" não está nem no sujeito, nem no objeto, tampouco na adequação entre um e outro. $\mathrm{O}$ verdadeiro encontra-se nas "articulações históricas de sua mútua modificação e constituição" (CANDIOTTO, 2006, p. 68). A história crítica do pensamento seria a história sempre provisória das "regras segundo as quais, a propósito de certas coisas, aquilo que um sujeito pode dizer pertence à questão do verdadeiro e do falso". (FOUCAULT, 1994b, p. 632, apud CANDIOTTO, 2006, p. $68)$.

Foucault chama de ética o trabalho pelo qual o sujeito constitui a si mesmo. Para entendermos melhor, cabe compreender o que significa moral. Por moral, podemos entender um conjunto de valores e regras que podem ser propostos prescritivamente aos indivíduos e aos grupos por uma série de instituições, tais como a família, as escolas, as igrejas, o próprio Estado. Entretanto, de outro lado, podemos entender por moral os comportamentos dos indivíduos à medida que eles se adaptam ou não às regras e aos valores que lhe são propostos. No primeiro caso podemos falar de "código moral", no segundo "moralidade dos comportamentos".

Uma ação moral não se reduz a um ato, um código, uma lei ou um valor. Toda ação moral é um misto entre a relação que ela tem com a realidade em que se situa e com o código ao qual se refere. Além disso, ela implica em uma relação com o próprio indivíduo que a pratica. Essa relação não é apenas conhecimento de si, mas constituição de si. Constituição de si como sujeito moral onde o indivíduo circunscreve a parte dele mesmo que constitui o objeto dessa prática moral. De certa forma, podemos dizer que o indivíduo não é um ser passivo a um código moral e a uma prática moral. Ao atuar com ambos ele atua sobre si mesmo, conhece a si mesmo, constitui a si mesmo, se põe à prova, aperfeiçoa-se e se transforma. Dessa forma, existe na moral este conjunto de valores e regras que se organizam em torno de um código, assim como uma série de ações e práticas realizadas pelos indivíduos que compõem esse quadro, na medida em que obedecem ou não. O terceiro elemento a ser incluído neste esquema é a ética, que aqui implica na relação do indivíduo consigo mesmo, na maneira pela qual ele se constitui como sujeito moral do código. Foucault não está interessado em uma genealogia dos "códigos morais" ou em uma genealogia da "moralidade dos comportamentos". O interesse de Foucault se dirige para a "genealogia da ética".

\begin{tabular}{|l|l|l|l|l|}
\hline Govista Dialectus & Ano 5 & n. 12 & Janeiro - Julho 2018 & p. 462-482 \\
\hline
\end{tabular}




\section{A URGÊNCIA DO PRESENTE: ATITUDE CRÍTICA E ÉTICA DA... Daniel Luís Cidade Gonçalves}

Podemos dizer então que para Foucault, o termo ética refere-se a todo esse domínio da constituição de si mesmo como sujeito moral. A ética faz referência à relação consigo mesmo, é um éthos, uma prática, um modo de ser. A liberdade por sua vez, deve ser praticada eticamente. "A liberdade é a condição ontológica da ética. Mas a ética é a forma refletida assumida pela liberdade". (FOUCAULT, 2006b, p. 267).

Neste contexto, convém entender a ética não como cumprimento de uma norma, mas como exercício de liberdade. De acordo com Foucault, não é totalmente necessário ligar problemas éticos ao conhecimento científico. Durante séculos temos nos convencido de que existem relações analíticas entre nossa ética pessoal e as grandes estruturas políticas, sociais e econômicas, e que por isso, não podemos mudar nada em nossa vida familiar, sexual, etc., sem arruinar nossa economia, nossa democracia e outros âmbitos da vida social. "Eu acho que temos que nos livrar desta ideia de uma ligação analítica ou necessária entre a ética e outras estruturas sociais, econômicas ou políticas." (FOUCAULT, 1984, p. 50).

Para Foucault, a ética não existe sem liberdade, portanto ela não existe sem uma atitude crítica que possibilite aos indivíduos constituírem a si mesmos de maneira livre, recusarem os modelos históricos que resultam em relações de saber/poder/subjetividade e problematizarem livremente tudo aquilo que considerem importante. Segundo Rajchman:

O questionamento do antropologismo por Foucault converte-se numa ética do livre pensamento: ao suspender a narrativa universalista e a segurança antropológica acerca de uma liberdade abstrata, Foucault dirige a nossa atenção para a liberdade bastante concreta de escrever, pensar e viver num questionamento permanente daqueles sistemas de pensamento e formas problemáticas de experiência em que nos encontramos. (RAJCHMAN. 1987, p. 11/12).

Ainda com Rajchman:

Se Foucault raras vezes usa a palavra "crítica" ou se descreve como um "teórico-crítico", isso deve-se, em parte a que a sua crítica é de uma espécie nova e específica que não emprega a linguagem familiar de alienação, mistificação e repressão. (RAJCHMAN, 1987, p. 69).

Isso ocorre, segundo Rajchman, porque Foucault pretende criar uma espécie diferente de "teoria crítica", que não seria hegeliana (porque não tem uma sociedade racional como objetivo), nem kantiana (por não ser normativa ou universalista). A crítica foucaultiana não se remete a uma visão global de sociedade, dirige-se "para

\begin{tabular}{|l|l|l|l|l|}
\hline Govista Dialectus & Ano 5 & n. 12 & Janeiro - Julho 2018 & p. 462-482 \\
\hline
\end{tabular}




\section{A URGÊNCIA DO PRESENTE: ATITUDE CRÍTICA E ÉTICA DA... Daniel Luís Cidade Gonçalves}

aquelas formas históricas da experiência cujas "políticas" nenhum Estado ou sociedade pode facilmente governar" (RAJCHMAN, 1987, p. 70).

Para Rajchman, a crítica foucaultiana difere-se do modelo tradicional que concentra-se na ideologia. A ideologia, entendida como o conjunto de crenças irracionais que nos afasta de nossos verdadeiros interesses, pode ser entendida como uma forma de dominação que, embora não se baseie na força, nos impede de lutar pela realização desses interesses ${ }^{6}$. Foucault nos mostra que o poder age de maneiras muito mais diretas e concretas do que pela inserção de crenças irracionais. O poder se dirige em direção da formação de nossos corpos e identidades. Não podemos "descobrir" nossos "verdadeiros interesses" pois eles não existem intrinsecamente, eles são historicamente constituídos através de práticas que podem ser mais ou menos livres. Isso suscita uma crítica pautada numa ética da liberdade, ou, numa "ética do livre pensamento". É justamente por deslocar tanto a questão do sujeito quanto a da verdade, que a crítica foucaultiana não poderia sustentar-se em outra base, exceto a da liberdade. Se tanto o sujeito quanto a verdade são constituídos historicamente, então não podemos falar em "nossos verdadeiros interesses" ou na "racionalidade universal de nossas práticas". Aquilo que irá se impor como verdadeiro ou necessário, depende diretamente da forma como nos constituímos. A crítica serve para manter a atitude perpétua de problematizarmos nossas práticas quando elas nos parecem prejudiciais, para que não aceitemos tão facilmente as práticas que se impõe, reivindicando valores de verdade ou racionalidade. Pela crítica, o nosso pensamento é constantemente submetido à análise e nossas práticas são questionadas sempre que necessário. A liberdade não se encontra em nossa natureza transcendental, mas em nossas capacidades de contestar e mudar nossas práticas, nossas verdades e até mesmo nossas subjetividades. Podemos dizer que, para Foucault, nossa liberdade não é antropológica, mas política. E isso nos remete, mais uma vez, a filosofia:

\footnotetext{
A filosofia de Foucault é o apelo crítico a essa liberdade real. Portanto, sua "verdade" é uma espécie diferente das verdades da ciência. A pesquisa filosófica é mais do que uma coleção sistemática de conhecimentos. É uma crítica que não tenta fundar o conhecimento, dotar a teoria de uma justificação ou defender a Razão, mas possibilitar novos modos de pensamento. Analisa como o conhecimento sobre nós mesmos está vinculado, de formas complexas, a técnicas de dominação, e vê a liberdade não como o fim da dominação ou como nossa remoção da história, mas como a revolta pela qual a história pode ser constantemente mudada. Assim, a
}

\footnotetext{
${ }^{6}$ Desmistificar uma ideologia seria descobrir estes interesses e assumi-los.

\begin{tabular}{|l|l|l|l|l|}
\hline Q ovista Qialectus & Ano 5 & n. 12 & Janeiro - Julho 2018 & p. 462-482 \\
\hline
\end{tabular}
}




\section{A URGÊNCIA DO PRESENTE: ATITUDE CRÍTICA E ÉTICA DA... Daniel Luís Cidade Gonçalves}

filosofia de Foucault não é prescritiva nem meramente descritiva. É ocasião, centelha, desafio. É risco; não é garantida, escorada ou a assegurada; permanece sempre sem um fim. (RAJCHMAN, 1987, p. 105).

\section{Conclusão}

A ideia a ser defendida aqui, é a de que existe um projeto crítico no pensamento de Foucault, que se distingue da crítica kantiana, hegeliana ou frankfurtiana e pressupõe um deslocamento em nossas concepções clássicas acerca do sujeito, da verdade e da filosofia. Indo mais além, longe de pressupor algum tipo de natureza humana ou verdade intrínseca, o projeto crítico foucaultiano sugere uma prática de subjetivação (que pode ser melhor compreendida com a análise do cuidado de si); uma concepção de verdade que resgata parcialmente o conceito de espiritualidade (resultando em um estudo acerca da parrhesia); e uma concepção filosófica que atende ao apelo da atualidade (ou a urgência do presente) e insere a filosofia no interior de uma relação com a política.

Antes de ir mais adiante, é necessário fazer uma ressalva importante. Sugerir que o projeto crítico foucaultiano remete a uma prática de subjetivação, que foi melhor estudada pelo autor em sua análise do cuidado de si, ou uma concepção de verdade que se remete à parrhesia, não implica em dizer que Foucault pretende resgatar o cuidado de si, a parrhesia, ou qualquer outra noção estudada (especialmente aquelas referentes à filosofia antiga). Foucault nos traz conceitos antigos, para nos mostrar como nós, seres humanos, nos deparamos com problemas diferentes no passado, e damos respostas diversas a estes problemas. Não se trata de resgatá-las, mas de compreender que não existe uma única resposta ideal a um problema, muito menos um único problema que possa ser levantado. Para Foucault (1984, p. 44) "não se pode encontrar a solução de um problema levantado em um outro momento por outras pessoas". Assim, é importante que fique claro que Foucault não pretende trazer do passado soluções para o presente, mas, de fato, acredita que estudar o passado pode nos ajudar muito na elucidação de nossos problemas atuais (que devem ser resolvidos por nós).

Entre as invenções culturais da humanidade há um tesouro de artifícios, técnicas, ideias, procedimentos, etc..., que não podem ser efetivamente reativas, mas pelo menos constituem, ou ajudam a constituir um certo ponto de vista que pode ser muito útil como uma ferramenta para analisar o que está acontecendo agora - e modifica-lo. (FOUCAULT, 1984, p. 49).

\begin{tabular}{|c|c|c|c|c|}
\hline Qevista Dialectus & Ano 5 & n. 12 & Janeiro - Julho 2018 & p. $462-482$ \\
\hline
\end{tabular}




\section{A URGÊNCIA DO PRESENTE: ATITUDE CRÍTICA E ÉTICA DA... Daniel Luís Cidade Gonçalves}

Os escritos de Foucault não são prescrições em um sentido forte do termo. Não existe para ele um modelo ideal de sujeito, uma forma utópica de governo, ao qual deveríamos seguir. Isso, contudo, não nos impede de dizer que os conceitos resgatados pelo autor não possam ser, de certa forma, uma sugestão. Se a filosofia de Foucault tem como alicerce a atitude crítica e a ética da liberdade, podemos sugerir que uma série de noções se apresentam para enriquecer e dar sentido a isto tudo. Para isso, podemos retomar especialmente três noções: o cuidado de si enquanto prática de subjetivação, a parrhesia enquanto forma de espiritualidade e a filosofia enquanto urgência do presente.

Como já visto, seria totalmente equivocado pressupor que Foucault teve a intenção de resgatar o cuidado de si (ou qualquer outra noção) em seus moldes antigos. Todavia, não nos parece tão equivocado sugerir que poderíamos recriá-lo. O sujeito se autoconstitui através de técnicas de si, muitas das quais encontra de antemão no contexto em que vive, mas também mistura (pelo menos em alguns casos) uma parcela de sua liberdade. Temos as práticas de subjetivação. Reconstruir o cuidado de si, em um contexto de atitude crítica (e ética do livre pensamento) implicaria na exigência de técnicas de si mais inclinadas às maneiras livres de autoconstituição, e menos voltadas à descoberta de uma verdade interior do indivíduo. Não atingiríamos nunca um modelo ideal de sujeito, o "ideal" seria sujeitos constituindo-se perpetuamente, levando sempre em consideração a importância de cuidar de si mesmos7 neste processo. Nesta problematização do cuidado de si, as análises foucaultianas não ditam verdades, mas servem de apoio no processo de busca, compreensão e construção. É no mínimo inspirador saber que o cuidado de si não implicava em um individualismo e que para que o cuidado dos outros fosse possível era antes necessário cuidar de si.

Mantendo as ressalvas anteriores, neste contexto, a noção de espiritualidade é resgatada em sua relação com a verdade (entendida aqui como veridição). Como já visto, Foucault não procura pela verdade das coisas, mas por suas veridições, ou seja, pelo modo como elas viriam a ser consideradas verdadeiras. Isso remete a um resgate do conceito de espiritualidade, na medida em que, algo não se torna verdadeiro exclusivamente devido as suas peculiaridades. O sujeito que considera algo verdadeiro, assim como as regras dos jogos de verdade em um determinado contexto, estão diretamente ligados, para que algo venha a ser verdadeiro. Assim, com o conceito de espiritualidade, o jogo do verdadeiro ou falso, remete tanto a transformações no sujeito

${ }^{7}$ E cuidar dos outros, visto que o cuidado de si pode ser uma prática social.

\begin{tabular}{|l|l|l|l|l|}
\hline Qonista Qialectus & Ano 5 & n. 12 & Janeiro - Julho 2018 & p. 462-482 \\
\hline
\end{tabular}




\section{A URGÊNCIA DO PRESENTE: ATITUDE CRÍTICA E ÉTICA DA... Daniel Luís Cidade Gonçalves}

quando a mudanças nas veridições contextualizadas. Indo mais além, não basta constatar este vínculo entre sujeito e verdade, Foucault almeja mais, é importante que a verdade não se encontre submissa aos interesses poucos. Voltamos à questão da ética e da crítica, mas mais ainda, nos dirigimos em direção à parrhesia, na medida em que ela representa muito mais do que o simples ato de dizer a verdade. A parrhesia diz respeito a um vínculo entre aquele que enuncia a verdade e aquilo que é enunciado. É preciso ter coragem, correr riscos. $\mathrm{O}$ risco externo de não ter uma boa aceitação a respeito daquilo que diz, e o risco interno de modificar a si mesmo de maneira irreversível. Com a parrhesia, Foucault não deseja apenas apontar a importância da noção de espiritualidade, ele quer resgatar a atitude crítica em nossa ética, impedir que nossas relações com a verdade sejam estagnadas, covardes, servis, inúteis. Suas considerações sobre a parrhesia política (democrática e autocrática), a parrhesia socrática e a parrhesia cínica, tornam-se uma caixa de ferramentas para problematizarmos nossa ética e nossa política atuais, sob o viés de uma relação corajosa com a verdade.

Foucault herda de Kant a tradição na qual a filosofia responde ao apelo da atualidade, ou seja, a "ontologia do presente". Para o filósofo francês, não se trata de resolver os tradicionais problemas filosóficos (vimos anteriormente como Foucault desloca muitos deles), mas utilizar a filosofia para responder “o que acontece agora?", ou, “o que se passa com nós, neste momento?". Neste contexto, as grandes obras de Foucault são um belo exemplo, na medida em que questionam o que acontece nos asilos, nas prisões, com a nossa sexualidade, sem tentar normativizar ou desvendar essências. Isso ocorre porque Foucault tem muito claro que cada época tem seus problemas e busca suas soluções como lhe convém. Como diz Paul Veyne (2009), em Foucault, o pensamento, a pessoa, para o Foucault, o passado é o "cemitério das verdades" (VEYNE, 2009, p. 45). Os contemporâneos de cada época encontram-se fechados em discursos (como se fossem aquários) e ignoram suas limitações. Segundo Veyne "os discursos variam através do tempo; mas, em cada época, passam por verdadeiros" (VEYNE, 2009, p. 19). É por estar consciente destes limites (por saber que vive em um aquário), que para o filósofo francês a filosofia se remete à urgência do presente. Sem isso, estaremos acusando de falsos aqueles discursos que, de fato, não possuem mais condições de serem verdadeiros (o aquário mudou), mas estaremos fazendo pouco para enxergar além de nossas próprias limitações. É por isso que a crítica é uma atitude permanente e a ética tem a liberdade (e o livre pensamento) como pré-

\begin{tabular}{|c|c|c|c|c|}
\hline Qevista Dialectus & Ano 5 & n. 12 & Janeiro - Julho 2018 & p. $462-482$ \\
\hline
\end{tabular}




\section{A URGÊNCIA DO PRESENTE: ATITUDE CRÍTICA E ÉTICA DA... Daniel Luís Cidade Gonçalves}

requisito. O projeto crítico foucaultiano dá mais sentido a toda sua obra. Suas arqueologias e genealogias enriquecem com os bons exemplos do autor sobre como seguir em frente, aceitando nossos limites e tentando ultrapassá-los frequentemente.

\section{REFERÊNCIAS}

CANDIOTTO, Cesar. Foucault: uma história crítica da verdade. Trans/Form/Ação, São Paulo, v. 29, n. 2, p.65-78, 2006. Disponível em: http://www2.marilia.unesp.br/revistas/index.php/transformacao/article/viewFile/914/81 9 Acesso em: 08 de julho de 2012.

CANDIOTTO, Cesar. Foucault e a crítica da verdade. Belo Horizonte: Autêntica; Curitiba: Champagnat, 2010.

CARDOSO JR, Hélio Rebello; OLIVA; Alfredo dos Santos. Parresia, prática de si e moraçl de código: mais um elo do problema do sentido histórico em Foucault. In: CANDIOTTO, Cesar; SOUZA, Pedro de (Orgs.). Foucault e o cristianismo. Belo Horizonte: Autêntica, 2012, p. 121 - 127.

FOUCAULT. Michel. O dossiê: últimas entrevistas. Tradução de Ana Maria de A. Lima e Maria da Glória R. da Silva. Rio de Janeiro: Livraria Taurus, 1984.

História da sexualidade 3: $\mathrm{O}$ cuidado de si. 4. ed. Tradução de Maria Thereza da Costa Albuquerque. Rio de Janeiro: Graal, 1985.

História da sexualidade 1: a vontade de saber. 11. ed. Tradução de Maria Thereza da Costa Albuquerque e J.A. Guilhon Albuquerque. Rio de Janeiro: Graal, $1988 \mathrm{a}$.

História da sexualidade 2: o uso dos prazeres. 5. ed. Tradução de Maria Thereza da Costa Albuquerque. Rio de Janeiro: Graal, 1988b.

O sujeito e o Poder. In: DREYFUS, Hubert; RABINOW, Paul. Michel Foucault: uma trajetória filosófica: para além do estruturalismo e da hermenêutica. Tradução de Vera Porto Carrero. Rio de Janeiro: Forense Universitária, 1995.

A verdade e as formas jurídicas. Tradução de Roberto Cabral de Melo Machado e Eduardo Jardim Morais. Rio de Janeiro: Nau, 1996

Hermenêutica do sujeito. 2.ed. Tradução de Márcio Alves da Fonseca e Salma Tannus Muchail. São Paulo: Martins Fontes, 2006a.

Ética, sexualidade, política: Ditos e escritos. Vol. V, 2. ed. Tradução de Elisa Monteiro e Inês Autran Dourado Barbosa. Rio de Janeiro: Forense Universitária, 2006b.

Le courage de la vérité: le gouvernement de soi et des autres II. Paris: Gallimard, 2009.

\begin{tabular}{|l|l|l|l|l|}
\hline Qevista Dialectus & Ano 5 & n. 12 & Janeiro - Julho 2018 & p. 462-482 \\
\hline
\end{tabular}




\section{A URGÊNCIA DO PRESENTE: ATITUDE CRÍTICA E ÉTICA DA... \\ Daniel Luís Cidade Gonçalves}

O governo de si e dos outros. Tradução de Eduardo Brandão. São Paulo: Martins Fontes, 2010.

GROS, Frédéric (org). Foucault: a coragem da verdade. Tradução de Marcos Marcionilo. São Paulo: Parábola, 2004.

Verità, soggettività, filosofia nell'ultimo Foucault, In: GALZIGNA, Mário (org). Foucault oggi. Milano, Feltrinelli, 2008, pp. 293-302. Tradução portuguesa de Selvino J. Assimann.

Situation du cours. In: FOUCAULT, Michel. Le courage de la vérité: le gouvernement de soi et des autres II. Paris: Gallimard, 2009, p. 314 - 328.

ORTEGA, Francisco. Amizade e estética da existência em Foucault. São Paulo: Graal, 1999.

RAJCHMAN, John. Foucault: A liberdade da filosofia. Tradução de Álvaro Cabral. Rio de Janeiro: Jorge Zahar, 1987.

VEYNE, Paul. Foucault: O pensamento a pessoa. Tradução de Luís Lima. Lisboa. Edições Texto e Grafia, 2009.

\begin{tabular}{|l|l|l|l|l|}
\hline Qevista Dialectus & Ano 5 & n. 12 & Janeiro - Julho 2018 & p. 462-482 \\
\hline
\end{tabular}

